ARTICLE

\title{
Selective ligand removal to improve accessibility of active sites in hierarchical MOFs for heterogeneous photocatalysis
}

Shaghayegh Naghdi (iD 1, Alexey Cherevan (10 1, Ariane Giesriegl1, Rémy Guillet-Nicolas 2,3, Santu Biswas ${ }^{4}$, Tushar Gupta (1) 1, Jia Wang1, Thomas Haunold', Bernhard Christian Bayer (1) 1, Günther Rupprechter (1) 1, Maytal Caspary Toroker (ID) ${ }^{4,5}$, Freddy Kleitz (i) ${ }^{2}$ \& Dominik Eder (iD ${ }^{1 凶}$

Metal-organic frameworks (MOFs) are commended as photocatalysts for $\mathrm{H}_{2}$ evolution and $\mathrm{CO}_{2}$ reduction as they combine light-harvesting and catalytic functions with excellent reactant adsorption capabilities. For dynamic processes in liquid phase, the accessibility of active sites becomes a critical parameter as reactant diffusion is limited by the inherently small micropores. Our strategy is to introduce additional mesopores by selectively removing one ligand in mixed-ligand MOFs via thermolysis. Here we report photoactive MOFs of the MIL125-Ti family with two distinct mesopore architectures resembling either large cavities or branching fractures. The ligand removal is highly selective and follows a 2-step process tunable by temperature and time. The introduction of mesopores and the associated formation of new active sites have improved the HER rates of the MOFs by up to $500 \%$. We envision that this strategy will allow the purposeful engineering of hierarchical MOFs and advance their applicability in environmental and energy technologies.

\footnotetext{
${ }^{1}$ Institute of Material Chemistry, Technische Universität Wien, 1060 Vienna, Austria. ${ }^{2}$ Department of Inorganic Chemistry - Functional Materials, Faculty of Chemistry, Universität Wien, 1090 Vienna, Austria. ${ }^{3}$ Normandie University, ENSICAEN, UNICAEN, CNRS, Laboratoire Catalyse et Spectrochimie, 14050 Caen, France. ${ }^{4}$ Department of Materials Science and Engineering, Technion - Israel Institute of Technology, Haifa 3600003, Israel. ${ }^{5}$ The Nancy and Stephen

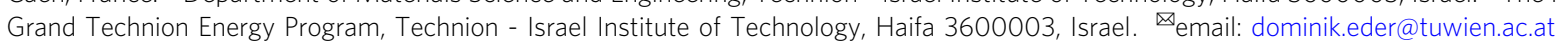


M etal-organic frameworks (MOFs) have recently gained tremendous interest as an innovative class of functional materials owing to their catalytically active metal-oxo clusters (secondary building units, SBUs), functional organic linkers, easily tunable physicochemical properties, and large surface areas along with a well-ordered porous structure ${ }^{1,2}$. First experiments have also shown great potential for MOFs as photocatalysts $^{3-7}$, as they can combine tunable light-harvesting (e.g., through the organic linker) and catalytic functions (e.g., through the inorganic nodes) along with an excellent reactant adsorption capability. The proximity of catalytic, electronic, and adsorption sites of MOFs allows for high turnovers and selectivity. Moreover, the inorganic nodes of MOFs resemble molecular catalytic centers emulating those of homogenous catalysts. This enables heterogeneous frameworks with well-defined active sites that allow in-depth fundamental studies on the reaction kinetics and pathways ${ }^{8}$. Therefore, MOFs can be seen as model systems for exploring advanced concepts, such as bridging homogeneous and heterogeneous photocatalysis as well as singlesite photocatalysis ${ }^{9}$.

However, kinetic restrictions upon reactant diffusion through (small) micropores in MOFs impose a serious challenge for their effective use as (photo)catalysts, in particular in liquid reaction media $^{3,4,10,11}$. A number of strategies have aimed at enhancing pore accessibility by expanding porosity in the original framework ${ }^{12,13}$. This can be achieved through synthesis or via post-synthetic modification that often relies on the reversible cleavage of selected bonds within the framework resulting in concurrent creation of larger pores ${ }^{14}$. The first category includes the use of elongated ligands ${ }^{15,16}$, metal-ligand-fragment coassembly 17,18 , and imperfect crystallization ${ }^{19,20}$ methods. The second category comprises the use of sacrificial soft or hard templates ${ }^{21-23}$, modulator-induced defect formation ${ }^{24}$, cation valence modulation ${ }^{25}$, and ligand exchange ${ }^{26}$. All of these methods, however, suffer from their limited applicability (i.e., only a few MOF structures or ligand types are suitable), a lack of control over shape, location, and spatial distribution of the introduced porosity, and an undesired loss of crystallinity, often accompanied by considerable pore collapse upon synthesis or post-processing. Recently, Feng et al. ${ }^{27}$ reported an intriguing route towards introducing hierarchical porosity in MOFs. This process, primarily demonstrated for $\mathrm{UiO}-66$, involves the synthesis of mixed-ligand MOFs consisting of organic linkers with different thermal stability, followed by selective linker removal through thermolysis.

One can envision that such MOFs with dual-porosity will advance their use in various applications, particularly when operating in liquid media. These may include drug delivery/ release, water purification, separation technologies, and liquidphase catalysis ${ }^{27,28}$. We envision the greatest benefits for energy conversion technologies, involving electrocatalysis and photocatalysis, where - in addition to the enhanced porosity - the partial ligand removal is expected to create unsaturated metal sites that can serve as adsorption sites for reactants and cocatalysts and thus as potential catalytic centers.

In this work, we synthesize a series of photoactive MOFs with two distinct dual-porosity characteristics. We unravel the mechanistic steps of ligand removal through powerful in situ techniques coupled with density-functional theory (DFT) simulations and provide an in-depth analysis of the resulting hierarchical pore structures. Furthermore, we explore the impact of the type and size of the mesopores on the MOFs photocatalytic performance towards hydrogen production. Our results demonstrate that small variations of the synthesis conditions can introduce two distinct, structurally different mesoporous geometries without noticeably altering the overall framework structure: cavities with ink-bottle pores and extended, interconnected fracture-type pores. Both geometries have significantly improved the hydrogen evolution rates of the MOFs, but it is the fracture-type geometry that has enhanced the activity by the highest factor. Therefore, this work provides an intriguing example of the potential of rationalized pore engineering towards advancing the performance of MOFs in various liquid phase applications.

\section{Results}

As-prepared mixed-ligand MOFs. We synthesized a series of isostructural mixed-ligand MIL-125-Ti-based MOFs with various ratios of terephthalic acid (BDC) to amino-terephthalic acid (BDC- $\mathrm{NH}_{2}$ ) (Supplementary Table 1), denominated as $x \mathrm{NH}_{2}$ MIL-125-Ti, with $x$ being the percentage of BDC- $\mathrm{NH}_{2}$. Due to the restrictions imposed by the limited solubility of the ligands, the samples were prepared following two routes that differ in the sequence of the precursor addition (Supplementary Fig. 1). For the samples with $2 \leq x \leq 10$, BDC- $\mathrm{NH}_{2}$ was added to a solution of BDC and titanium (IV) isopropoxide (TTIP) (route 1), while for the samples with $50 \leq x \leq 80 \mathrm{BDC}$ was added to a solution of BDC-NH $\mathrm{N}_{2}$ and TTIP (route 2). For details refer to the Supplementary Information. The actual content of each ligand was quantified by ${ }^{1}$ HNMR spectroscopy (Supplementary Table 4) and fits very well with the targeted ratios.

$\mathrm{X}$-ray diffraction (XRD) revealed that all synthesized MOFs are highly crystalline and consist of the expected crystal structure of MIL made of $\mathrm{Ti}_{8} \mathrm{O}_{4}(\mathrm{OH})_{4}$ clusters (SBU) connected via organic ligands (Supplementary Fig. 2a) ${ }^{29,30}$. It also confirms the absence of any impurity compounds or secondary phases. Note that the variation of the ligand has not affected the unit cell of the MOFs in a significant way, which demonstrates that both ligands are akin in terms of coordination directionality and size ${ }^{31}$. Interestingly, all samples exhibit a small diffraction peak at $2 \theta=13.6^{\circ}$, whose intensity decreases with increasing $\mathrm{BDC}-\mathrm{NH}_{2}$ content in relation to the MOF peaks. This feature has not been reported before in literature. The simulated XRD pattern (Supplementary Fig. 2b) reveals that this peak is associated with the presence of solvent molecules (i.e., DMF) incorporated within the micropores during the synthesis. The peak intensity correlates inversely to the amount of the solvent, hence the peak increases with the evaporation of solvent molecules upon heat treatment (Supplementary Fig. 5).

The crystalline nature of the as-prepared mixed-ligand MOFs was further investigated by transmission electron microscopy (TEM). The insets in Fig. 1 show typical bright-field (BF) TEM images of individual particles of (a) $5 \% \mathrm{NH}_{2}$-MIL and (b) $50 \%$
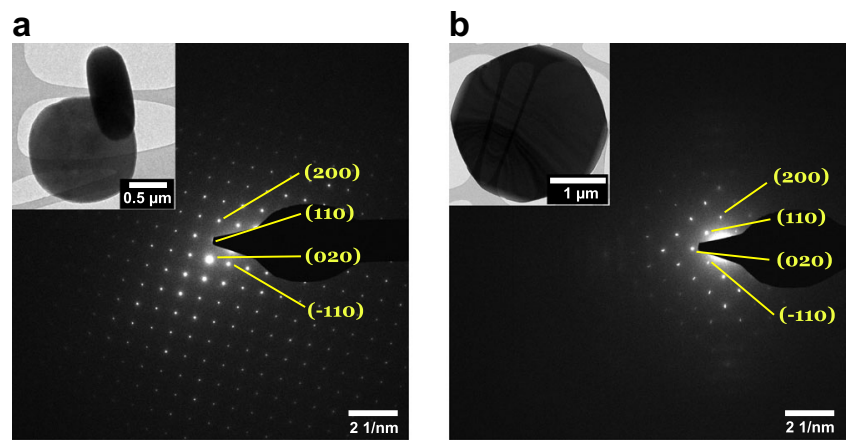

Fig. 1 Crystallinity of as-prepared mixed-ligand MOFs. SAED patterns recorded from an individual particle (BF TEM shown as insets) of asprepared $5 \%$ (a) and $50 \% \mathrm{NH}_{2}-\mathrm{MIL}(\mathbf{b})$. All SAED patterns were indexed using the cif file of pure MIL-125-Ti-based MOF $^{30}$ viewed along the [001] zone axis with salient reflections labeled. 
$\mathrm{NH}_{2}$-MIL and reveal that the MOF particles are generally diskshaped with regular facets and uniform size and shape. The observed homogenous contrast across individual particles suggests a single-crystalline nature. This was confirmed by the corresponding selected area electron diffraction (SAED) patterns, which confirm the expected structure and the absence of additional phases and impurities ${ }^{30}$.

The formation of mixed-ligand MOFs was also analyzed by diffuse reflectance infrared fourier transform spectroscopy (DRIFTS). Supplementary Figure 3 shows the corresponding spectra of both single-ligand MOFs (MIL, $\mathrm{NH}_{2}$-MIL) and two mixed-ligand MOFs (10\% and $50 \% \mathrm{NH}_{2}$-MIL) at room temperature, highlighting the characteristic bands. The bands in the range between 3680 and $3660 \mathrm{~cm}^{-1}$ can be assigned to intrinsic $\mathrm{OH}$ groups of the $\mathrm{Ti}_{8} \mathrm{O}_{8}(\mathrm{OH})_{4}$ clusters 32,33 , as also reported for structurally closely-related $\mathrm{Zr} \mathrm{MOF}{ }^{34}$. Note that this feature is often a superposition of several closely positioned bands resulting from local structural variations caused by missing or singly coordinated ligands, trapped solvent molecules, or differently coordinated aqua and hydroxo groups ${ }^{33}$.

The two broad bands centered at 3517 and $3384 \mathrm{~cm}^{-1}$ and their pronounced shoulders at lower wavenumbers can be assigned to asymmetric and symmetric $\mathrm{NH}$ vibrations and thus confirm the presence of the BDC- $\mathrm{NH}_{2}$ ligands in the respective MOFs. Note that in the mixed-ligand MOF, both bands are redshifted compared to the single-ligand $\mathrm{NH}_{2}$-MIL-125, which indicates a certain degree of $\mathrm{H}$-bonding ${ }^{35}$.

The bands at 1962 and $1935 \mathrm{~cm}^{-1}$ feature the coordination of the ligands to the SBU characteristic for MIL (BDC) and $\mathrm{NH}_{2}-$ MIL (BDC- $\mathrm{NH}_{2}$ ), respectively. Note that the mixed-ligand MOFs contain both bands with intensities that correspond well to the respective ligand ratios. A similar superposition of $\mathrm{BDC}-\mathrm{NH}_{2}$ and $\mathrm{BDC}$ is shown by the $\mathrm{CH}$ bending overtones in the range between 1800 and $1900 \mathrm{~cm}^{-1}$. In the low wavenumber region, the pronounced $\mathrm{CH}$ band at $1020 \mathrm{~cm}^{-1}$ seems unique for the BDCcontaining MOFs and can thus be considered a fingerprint vibration. The peaks at 1160 and $\sim 1710 \mathrm{~cm}^{-1}$ belong to free $\mathrm{C}-\mathrm{O}$ and $\mathrm{C}=\mathrm{O}$ stretching vibrations, respectively, likely corresponding to the presence of dangling ligands ${ }^{36}$. The characteristic bands are summarized in Supplementary Table 2.

Structural changes upon heat treatment. The single-ligand and mixed-ligand MOFs were subjected to heating in the air up to $600{ }^{\circ} \mathrm{C}$. Thermogravimetric analysis (TGA) reveals that both single-ligand MOFs experience a significant weight loss above $300^{\circ} \mathrm{C}$ (Supplementary Fig. 4a, b), which is associated with an endothermic decomposition of the organic linkers (Supplementary Fig. 4c). Note, that the onset temperature of this weight loss depends on the type of ligand. The decomposition of $\mathrm{BDC}-\mathrm{NH}_{2}$ in $\mathrm{NH}_{2}$-MIL proceeds via a 2-step process that starts just above $300{ }^{\circ} \mathrm{C}$ and concludes at $550{ }^{\circ} \mathrm{C}$, the reason of which will be explained below. In contrast, the BDC linker in MIL decomposes within a narrower temperature window between $430^{\circ} \mathrm{C}$ and $490^{\circ} \mathrm{C}$. The thermal removal of the organic compounds in the mixed-ligand MOFs follows this trend (Supplementary Fig. 4b, c), with the onset temperature increasing upon increasing amino content. This implies that the thermal removal of $\mathrm{BDC}-\mathrm{NH}_{2}$ in the amino-rich samples is kinetically more challenging than in the samples with lower $\mathrm{BDC}-\mathrm{NH}_{2}$ contents. Overall, these results confirm that $\mathrm{BDC}-\mathrm{NH}_{2}$ is more thermolabile than $\mathrm{BDC}$, and that heating at temperatures between $300{ }^{\circ} \mathrm{C}$ and $350^{\circ} \mathrm{C}$ allows for the selective removal of $\mathrm{BDC}-\mathrm{NH}_{2}$ from all MOF samples.

The structural changes upon heating up to $550^{\circ} \mathrm{C}$ in the air were also investigated with in situ XRD (Supplementary Fig. 5a). Selected XRD patterns for the most characteristic temperatures
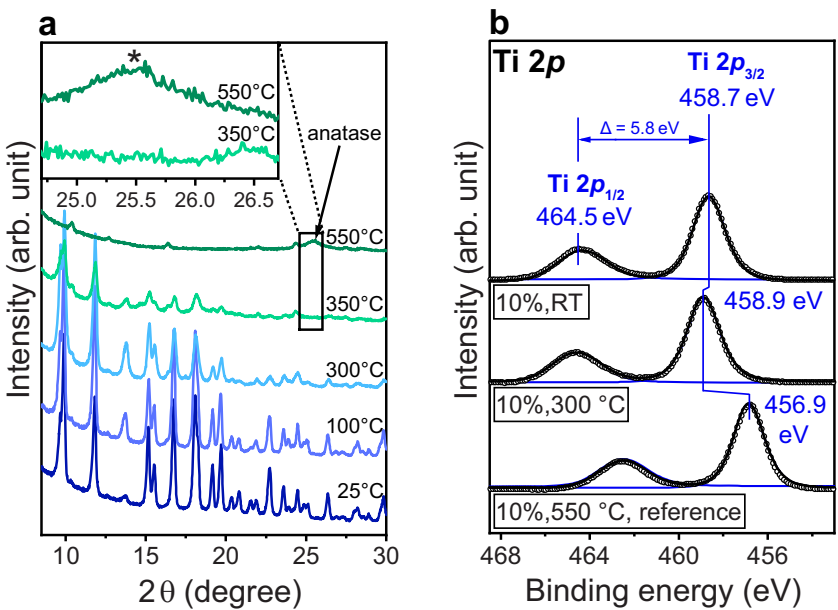

Fig. 2 Characterization of $10 \% \mathrm{NH}_{2}-\mathrm{MIL}$ upon heat treatment. a In situ XRD patterns collected during heating in air $\left(0.5 \mathrm{~mL} \mathrm{~min}^{-1}\right)$ up to $550^{\circ} \mathrm{C}$ $\left(5^{\circ} \mathrm{C} \mathrm{min}-1\right)$. b XPS Ti $2 p$ spectra of as-prepared $10 \% \mathrm{NH}_{2}-\mathrm{MIL}$, and after heat treatments in air at $300^{\circ} \mathrm{C}$ and $550^{\circ} \mathrm{C}(5 \mathrm{~h})$. The shift in binding energies at $550^{\circ} \mathrm{C}$ indicates the transformation of the MOF structure into $\mathrm{TiO}_{2}$, which correlates well with the appearance of the diffraction at $25.4^{\circ}$ (asterisk) characteristic of anatase (inset of Fig. 2a). XRD and XPS of other MOF samples can be found in Supplementary Figs. 5-7.

are summarized in Fig. 2a for $10 \% \mathrm{NH}_{2}$-MIL. Importantly, heating up to $300^{\circ} \mathrm{C}$ has neither affected the crystalline structure of the MOFs noticeably, nor the average size and morphology of the MOF particles (Supplementary Fig. 6 and Table 3). Note that the appearance of the peak at $13.6^{\circ}$ indicates the removal of DMF, in accordance with the simulated XRD pattern (Supplementary Fig. 2b). Further heating to $400^{\circ} \mathrm{C}$ has only led to a decrease in diffraction intensity, while the characteristic pattern of the MOF structure remains largely preserved. Note that this agrees well with TGA data, which indicate the degradation of BDC- $\mathrm{NH}_{2}$ in this temperature window (Supplementary Fig. 4). Finally, the typical MOF reflections vanished above $500^{\circ} \mathrm{C}$, which agrees with the degradation of BDC. Interestingly, the pattern at $550^{\circ} \mathrm{C}$ exhibits new peaks, the most prominent being at $25.4^{\circ}$, which can be assigned to the anatase phase and likely correspond to tiny particles of $\mathrm{TiO}_{2}$ formed upon complete removal of all organic species 37,38 .

To examine whether or not ultrafine $\mathrm{TiO}_{2}$ nanoclusters $(\sim 1 \mathrm{~nm})$ had already been formed at lower temperatures, i.e. upon removal of $\mathrm{BDC}-\mathrm{NH}_{2}$, the annealed samples were further studied by TEM, SAED, Raman, and X-ray photoelectron spectroscopy (XPS). Figure $2 \mathrm{~b}$ compares XPS Ti $2 p$ spectra of as-prepared $10 \% \mathrm{NH}_{2}-\mathrm{MIL}$ and the samples heat-treated at $300^{\circ} \mathrm{C}$ and $550{ }^{\circ} \mathrm{C}$ for $5 \mathrm{~h}$. The binding energies of Ti $2 p_{1 / 2}$ and $2 p_{3 / 2}$ at $464.5 \mathrm{eV}$ and $458.7 \mathrm{eV}$, respectively, fit very well with those reported in literature ${ }^{39}$ confirming the presence of intact $\mathrm{Ti}_{8} \mathrm{O}_{4}(\mathrm{OH})_{4}$ clusters. The heat treatment at $300^{\circ} \mathrm{C}$ does not affect the oxidation state, and hence the structure, in a noticeable way. This was also observed for the $5 \%$ and $50 \% \mathrm{NH}_{2}-\mathrm{MIL}$ samples (Supplementary Fig. 7). In contrast, heat treatment at $550{ }^{\circ} \mathrm{C}$ results in a considerable shift in the binding energy of $2 \mathrm{eV}$ to energies characteristic of anatase- $\mathrm{TiO}_{2}{ }^{40}$. This confirms that the transformation of $10 \% \mathrm{NH}_{2}$-MIL to $\mathrm{TiO}_{2}$ occurs only at temperatures higher than $500^{\circ} \mathrm{C}$ associated with the removal of both ligands, as indicated by XRD (Fig. 2a).

Figure 3 shows TEM images and the SAED patterns for the $5 \%, 10 \%$, and $50 \% \mathrm{NH}_{2}$-MIL samples heat-treated at $300^{\circ} \mathrm{C}$ for $5 \mathrm{~h}$. The results reveal no noticeable changes in morphology and size of the MOF particles, in line with scanning electron 

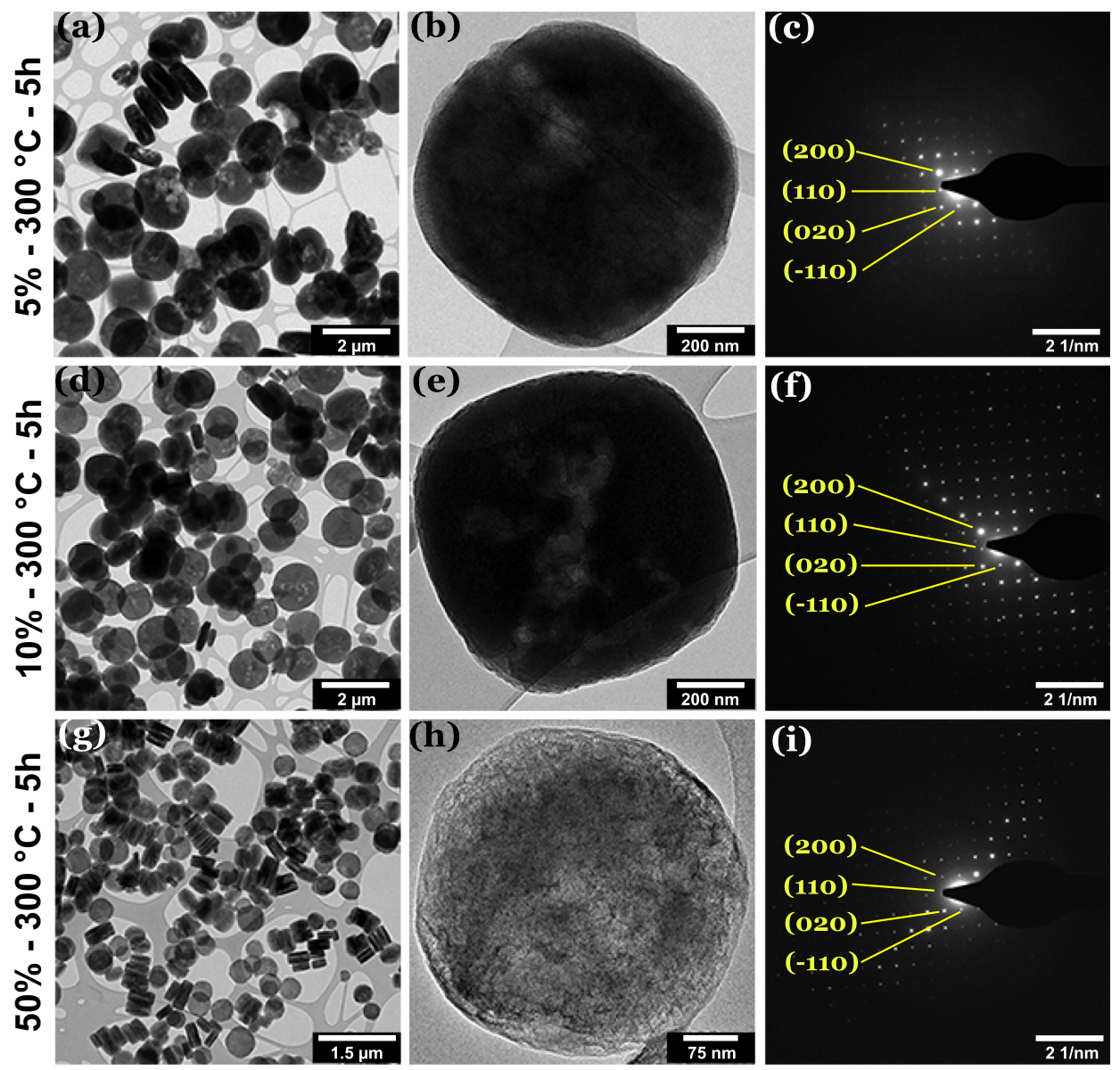

Fig. 3 TEM/SAED analysis of MOFs heated at $300{ }^{\circ} \mathbf{C}$ for $\mathbf{5} \mathbf{h}$. a-c BF-TEM images of $5 \% \mathrm{NH}_{2}-\mathrm{MIL}$ as an overview (a) and of an individual MOF particle (b) along with the corresponding SAED pattern (c). d-f and $\mathbf{g}-\mathbf{i}$ show the corresponding BF TEM and SAED data for the $10 \%$ and $50 \% \mathrm{NH}_{2}-\mathrm{MIL}_{\text {, }}$ respectively. All SAED patterns have been indexed using the cif file and fit the MIL-125-Ti structure, ${ }^{30}$ viewed along the [001] zone axis. No indications of other phases were detected in the SAED data.

microscope (SEM) observations (Supplementary Fig. 6). Note that the $\mathrm{BF}$ images are taken from individual particles of $5 \%$ and $10 \% \mathrm{NH}_{2}$-MIL show some bright areas indicative of material removal. In contrast, the $50 \% \mathrm{NH}_{2}$-MIL samples exhibit a brighter contrast that indicates a more significant material loss that seems to affect the framework preferentially in plane perpendicular to the [001] axis (see low-magnification image in Fig. $3 g$ ). SAED confirms the preservation of the single-crystalline MIL-125 structure in all samples. Crucially, the patterns show no diffraction spots indicative of $\mathrm{TiO}_{2}$ or other minority phases. Note that SAED is more sensitive towards short-range ordering than $\mathrm{XRD}^{41,42}$, which excludes the formation of very fine clusters of $\mathrm{TiO}_{2}$. In contrast, heat treatment at $550^{\circ} \mathrm{C}$ (Supplementary Fig. 8) results in either transformation to anatase $\mathrm{TiO}_{2}$ (e.g., $10 \%$ $\mathrm{NH}_{2}-\mathrm{MIL}$ ) or a complete structural damage and pore collapse (e.g., $50 \% \mathrm{NH}_{2}$-MIL).

These findings are supported by Raman spectroscopy (Supplementary Fig. 9). Like SAED, Raman is more sensitive to short-range ordering than $\mathrm{XRD}^{42}$. The spectra of as-prepared MOFs exhibit distinct peaks that can be correlated to the MIL structure $^{43}$. Note that the MIL structure of the MOFs is largely preserved at $300{ }^{\circ} \mathrm{C}$. Importantly, no signs of anatase- $\mathrm{TiO}_{2}{ }^{44}$ or other impurity phases were observed. The situation is different for samples heat-treated at $550{ }^{\circ} \mathrm{C}$, which show features characteristic of anatase- $\mathrm{TiO}_{2}{ }^{44}$.

The combined results of XRD, DRIFTS, TGA/differential scanning calorimetry (DSC), Raman, XPS, and TEM/SAED thus confirm that the heat treatment at $300^{\circ} \mathrm{C}$ allows for selective removal of $\mathrm{BDC}-\mathrm{NH}_{2}$ from the mixed-ligand MOFs, while preserving the characteristic structure.

Effect of temperature on selective ligand removal mechanism. The selective removal of $\mathrm{BDC}-\mathrm{NH}_{2}$ from the mixed-ligand MOFs was investigated in detail with in situ DRIFTS during heating up to $600{ }^{\circ} \mathrm{C}$. Figure $4 \mathrm{a}$ shows exemplary spectra of $10 \% \mathrm{NH}_{2}-\mathrm{MIL}$ acquired at room temperature (RT), $300^{\circ} \mathrm{C}$ and $550^{\circ} \mathrm{C}$ and presented for the range 2200 to $3800 \mathrm{~cm}^{-1}$ (for the entire series of this and the other samples, refer to Supplementary Figs. 10-12). Particular interest lies in the bands between 3680 and $3600 \mathrm{~cm}^{-1}$, which correspond to intrinsic $\mathrm{OH}$ groups of the $\mathrm{Ti}_{8} \mathrm{O}_{8}(\mathrm{OH})_{4}$ clusters $^{32,33}$. The respective evolution plots for these bands are shown in Fig. $4 \mathrm{~b}$ and Supplementary Fig. 11 and reveal that the heating-induced structural changes can be categorized into three thermal regimes:

In the $1^{\text {st }}$ regime between $290^{\circ} \mathrm{C}$ and $350{ }^{\circ} \mathrm{C}$, the band at $3660 \mathrm{~cm}^{-1}$, which is associated with $\mathrm{OH}$ groups of the $\mathrm{Ti}_{8} \mathrm{O}_{8}(\mathrm{OH})_{4}$ cluster that are $\mathrm{H}$-bonded with DMF molecules (inset Fig. 4b), disappears, while a new band simultaneously arises at $3682 \mathrm{~cm}^{-1}$. According to DFT simulations (inset Fig. 4b), this band is characteristic of the formation of free $\mathrm{OH}$ groups, i.e. without $\mathrm{H}$-bonding. The simultaneous decrease of the $\mathrm{CH}$ vibrations at 2932 and $2833 \mathrm{~cm}^{-1}$, which are associated with DMF molecules trapped within the micropores after the 


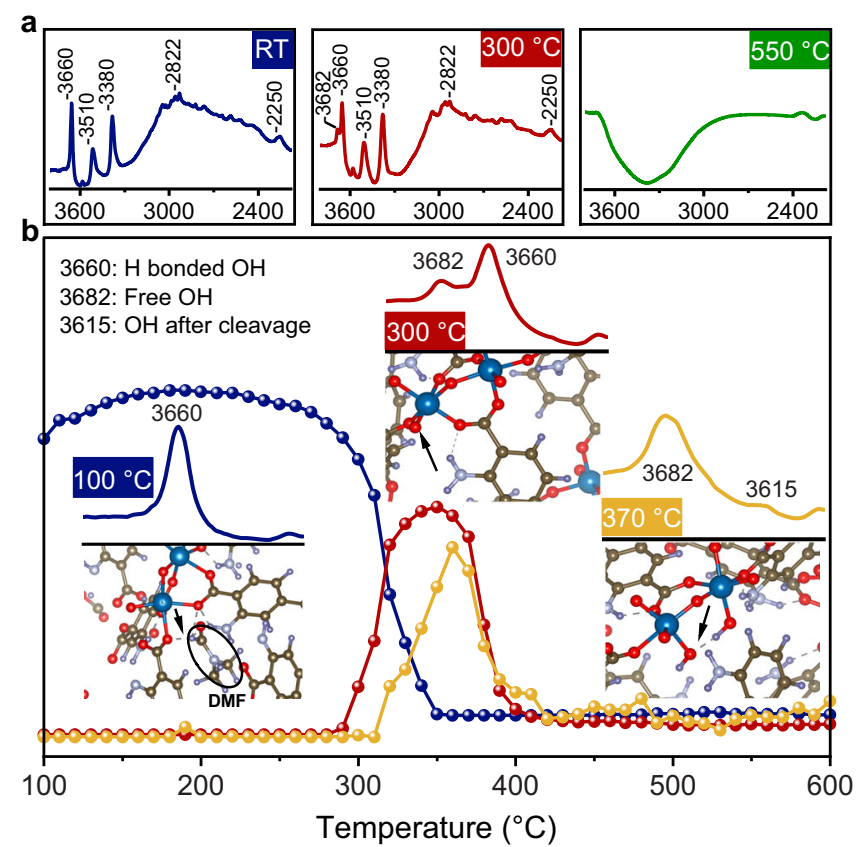

Fig. 4 In situ DRIFTS study of 10\% $\mathrm{NH}_{2}-\mathrm{MIL}$ during heating up to $600^{\circ} \mathrm{C}$. a Example spectra taken at room temperature (RT), $300^{\circ} \mathrm{C}$ and $550^{\circ} \mathrm{C}$. b Selected IR bands and their corresponding thermal evolution plots. The insets show a schematic representation of the structural feature as revealed by DFT simulations: the bands correspond to $\mathrm{OH}$ groups that are $\mathrm{H}$-bonded to trapped DMF molecules $\left(3660 \mathrm{~cm}^{-1}\right)$, free $\mathrm{OH}$ groups formed after DMF removal $\left(3682 \mathrm{~cm}^{-1}\right)$, and $\mathrm{OH}$ groups formed after partial or complete cleavage of the BDC- $\mathrm{NH}_{2}$ linker from the cluster $\left(3615 \mathrm{~cm}^{-1}\right)$.

synthesis $^{36}$, suggests that this $\mathrm{OH}$-band blue-shift is a consequence of solvent removal upon thermal evaporation (Supplementary Fig. 11b). Above $350^{\circ} \mathrm{C}$, the $\mathrm{OH}$-band at $3682 \mathrm{~cm}^{-1}$ vanishes due to dehydroxylation of the clusters similar to other MOFs ${ }^{45}$.

At $310^{\circ} \mathrm{C}$, a new band arises at $3615 \mathrm{~cm}^{-1}$. The simultaneous decrease of the band at $1595 \mathrm{~cm}^{-1}$ (Supplementary Fig. 11a), which correlates to the $\mathrm{COO}^{-}$vibrations of $\mathrm{BDC}^{-\mathrm{NH}_{2}}$ coordinating to the $\mathrm{Ti}_{8} \mathrm{O}_{8}(\mathrm{OH})_{4}$ cluster 6 , indicate bond cleavage and the formation of new $\mathrm{OH}$ groups. DFT studies (Supplementary Fig. 17) confirm that the new band at $3615 \mathrm{~cm}^{-1}$ is related to new $\mathrm{OH}$ groups at the SBU arising from bond cleavage of the SBUBDC- $\mathrm{NH}_{2}$ coordination (Fig. $4 \mathrm{~b}$ ). The absence of any changes of the $\mathrm{COO}^{-}$vibration of the BDC coordination $\left(1943 \mathrm{~cm}^{-1}\right)$ further confirms that bond cleavage at this temperature affects solely the $\mathrm{BDC}-\mathrm{NH}_{2}$ ligand.

This bond cleavage is accompanied by decarboxylation, since no bands related to $\mathrm{C}=\mathrm{O}$ or $\mathrm{C}-\mathrm{O}$ vibrations appeared during heating. In addition, the bands of $\mathrm{NH}$ and $\mathrm{CN}$ are largely unchanged, which suggests that at this stage the cleaved BDC$\mathrm{NH}_{2}$ ligands remain in the framework in the form of singlycoordinated amino species. This is supported by ${ }^{1} \mathrm{HNMR}$, which confirms the presence of 2 -aminobenzoic acid and excludes the formation of aniline that would be formed upon complete bond cleavage (Supplementary Fig. 15).

In the 2 nd regime between $350^{\circ} \mathrm{C}$ and $400^{\circ} \mathrm{C}$, the $\mathrm{BDC}-\mathrm{NH}_{2}$ related $\mathrm{COO}^{-}$vibrations at $1595 \mathrm{~cm}^{-1}$ decrease further and disappear at $410^{\circ} \mathrm{C}$, which points at the cleavage of the second ligand-cluster bond and decarboxylation to aniline. The simultaneous decrease of the $\mathrm{CN}$ and $\mathrm{NH}$ bands indicates that aniline degrades immediately after cleavage to benzene, $\mathrm{NO}_{\mathrm{x}}$ and water, as suggested by Feng et $\mathrm{al}^{27}$. This is confirmed by ${ }^{1} \mathrm{HNMR}$ spectroscopy (Supplementary Fig. 15). The residual weak $\mathrm{CN} / \mathrm{NH}$ peaks may be attributed to kinetic limitations associated with removing the decomposition products that are trapped in the framework, in line with XRD and TGA data. Note that the BDC characteristic $\mathrm{CH}$ band at $1020 \mathrm{~cm}^{-1}$ remains unchanged, which documents the high selectivity of this process towards BDC- $\mathrm{NH}_{2}$ removal.

In the $3 \mathrm{rd}$ regime beyond $400^{\circ} \mathrm{C}$ the peak at $1020 \mathrm{~cm}^{-1}$ decreases considerably at $500^{\circ} \mathrm{C}$ and vanishes at $550{ }^{\circ} \mathrm{C}$, which indicates cleavage and decomposition of the BDC ligand. This is accompanied by the disappearance of residual $\mathrm{CN}$ and $\mathrm{NH}$ peaks, which suggests the release of residual trapped $\mathrm{NH}$-containing degradation products upon framework collapse. Note that the broad peak at around $3400 \mathrm{~cm}^{-1}$ in the spectrum at $550{ }^{\circ} \mathrm{C}$ indicates a broad energy dispersion of $\mathrm{OH}$ bands likely related to the formation of $\mathrm{TiO}_{2}$ observed in XRD and SAED.

Isothermal ligand removal. The MOFs were heated up to $300^{\circ} \mathrm{C}$ and kept at that temperature for $20 \mathrm{~h}$. We conducted in situ XRD studies of $2 \%, 10 \%$, and $50 \% \mathrm{NH}_{2}-\mathrm{MIL}$, which indicated no changes in the crystal structure upon dwelling at $300{ }^{\circ} \mathrm{C}$ (Supplementary Fig. 13).

The DRIFTS spectra of $10 \% \mathrm{NH}_{2}$-MIL for different durations upon dwelling at $300{ }^{\circ} \mathrm{C}$, along with the temporal evolution plots of selected IR bands, are shown in Fig. 5 (for $50 \% \mathrm{NH}_{2}$-MIL refer to Supplementary Fig. 14). Within the first $60 \mathrm{~min}$, the vibrations at 2932 and $2833 \mathrm{~cm}^{-1}$ related to DMF disappear, and simultaneously the $\mathrm{H}$-bonded $\mathrm{OH}$ groups $\left(3660 \mathrm{~cm}^{-1}\right)$ transform to their free form $\left(3682 \mathrm{~cm}^{-1}\right)$ due to solvent evaporation. Note that the main framework is still intact at this stage, as we observed no significant changes in bands intensity of the amino groups, i.e., $1252 \mathrm{~cm}^{-1}(\mathrm{CN})$ and $3380 \mathrm{~cm}^{-1}(\mathrm{NH})$. This is supported by ${ }^{1} \mathrm{HNMR}$ spectroscopy (Supplementary Fig. 15), which reveals that the typical features expected from BDC (8.04 ppm) and $\mathrm{BDC}-\mathrm{NH}_{2}(7.77,7.39,7.02 \mathrm{ppm})^{46}$ are present in the samples before and after heat treatment for $1 \mathrm{~h}$ without noticeable changes in intensity.

After about $1 \mathrm{~h}$, the new $\mathrm{OH}$ band at $3615 \mathrm{~cm}^{-1}$ associated with bond cleavage of the $\mathrm{BDC}-\mathrm{NH}_{2}$ coordination appears. Simultaneously, the BDC- $\mathrm{NH}_{2}$ related $\mathrm{COO}^{-}$band $\left(1955 \mathrm{~cm}^{-1}\right)$, $\mathrm{NH}$-band $\left(3380 \mathrm{~cm}^{-1}\right)$, and $\mathrm{CN}$-band $\left(1252 \mathrm{~cm}^{-1}\right)$ decrease, while the BDC-related bands at 1943 and $1020 \mathrm{~cm}^{-1}$ remain largely unchanged. This demonstrates a bond cleavage of only the BDC- $\mathrm{NH}_{2}$ linker. Note, however, that, in contrast to ligand removal upon raising the temperature, where the $\mathrm{COO}^{-}$band decreases noticeably before the NH-band (Fig. 4b), the decrease in the $\mathrm{COO}^{-}$and $\mathrm{NH}$ bands in the isothermal process occurs nearly at the same time (Fig. 5b). This suggests that the second bond cleavage starts well before the completion of the first. Again, this can be confirmed by ${ }^{1} \mathrm{HNMR}$, where the spectrum taken after $5 \mathrm{~h}$ shows no signs of $\mathrm{BDC}-\mathrm{NH}_{2}$ and only small amounts of 2-amino-benzoic acid species (7.92, 7.25, 7.15, $6.91 \mathrm{ppm}$ ) with most of them having proceeded to degrade into gaseous $\mathrm{NO}_{\mathrm{x}}$, benzene, and water ${ }^{27}$. Finally, cleavage, decarboxylation, and degradation of the $\mathrm{BDC}-\mathrm{NH}_{2}$ linker is completed after about $6 \mathrm{~h}$. The situation is very similar for the $50 \% \mathrm{NH}_{2}-$ MIL sample (Supplementary Fig. 15); note, however, that the cleavage of BDC- $\mathrm{NH}_{2}\left(3615 \mathrm{~cm}^{-1}\right)$ appears to start earlier, while the complete removal takes more time compared with the $10 \%$ $\mathrm{NH}_{2}$-MIL. Crucially, the BDC-related features in DRIFTS and NMR spectroscopy remain unchanged in all samples even after $20 \mathrm{~h}$ of heat treatment. This confirms the high selectivity towards removal of $\mathrm{BDC}-\mathrm{NH}_{2}$.

Porosity and specific surface area. The effect of selective linker removal on the porosity and pore architecture of the MOFs was 

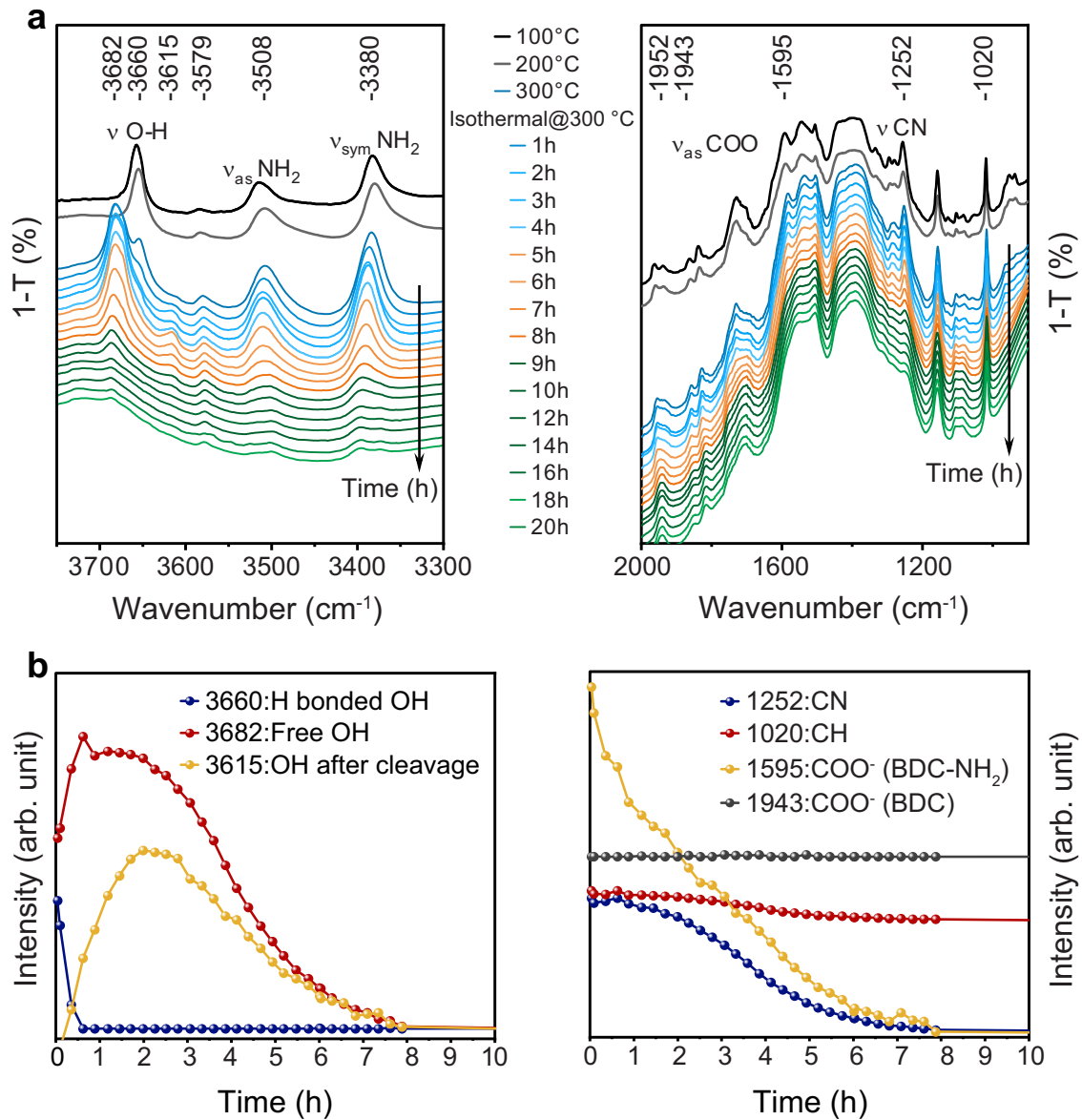

Fig. 5 Isothermal in situ DRIFTS study of $\mathbf{1 0} \% \mathbf{N H}_{\mathbf{2}}-\mathbf{M I L}$. a DRIFTS spectra were collected during heating up to $300^{\circ} \mathrm{C}$ and dwelling for $20 \mathrm{~h}$. $\mathbf{b}$ Evolution of characteristic IR bands during the dwelling.

investigated by physisorption with argon at $87 \mathrm{~K}$ (Fig. 6). The apparent surface area of the mixed-ligand MOFs decreases with increasing BDC- $\mathrm{NH}_{2}$ content from $1400 \mathrm{~m}^{2} \mathrm{~g}^{-1}$ to $\sim 1200 \mathrm{~m}^{2} \mathrm{~g}^{-1}$. As-prepared mixed-ligand MOFs exhibit a type I(a) isotherm typical of microporous materials with pores below $1 \mathrm{~nm}$ (Fig. 6a, d). The plots also show a small $\mathrm{H} 4$ hysteresis loop indicative of the presence of intercrystalline porosity, possibly stemming from an incomplete fusing of nuclei upon crystallization ${ }^{47}$. Furthermore, all samples exhibit a sharp and narrow pore size distribution (Fig. 6b, e and Supplementary Fig. 16), centered at $0.6 \mathrm{~nm}$, thus confirming the high quality of the samples. Heat treatment at $300{ }^{\circ} \mathrm{C}$ leads to a diminution of the total amount of micropores and a noticeable decrease of the BET apparent surface area (Supplementary Table 5). The isotherms exhibit hybrid type I(a)/IV(a) with a hysteresis loop at higher pressures, which confirms the introduction of mesopores.

The effect of heat treatment on the porosity of MOFs, however, strongly depends on the initial BDC- $\mathrm{NH}_{2}$ content. The samples with low BDC- $\mathrm{NH}_{2}$ contents $\left(2 \%, 5 \%\right.$, and $10 \% \mathrm{NH}_{2}$ MIL) experience a strong decrease in apparent surface area by about $40-50 \%$, which is accompanied by a substantial hysteresis loop of type $\mathrm{H} 5$ associated with a pore structure containing both open and partially blocked mesopores. The visible tailing in the desorption curve indicates that a small portion of the network is affected by pore blocking and/or cavitation effects (Fig. 6 and Supplementary Fig. 16 ${ }^{47}$. As a first approximation, such pores can be seen as large cavities, with pore size distribution from 5 to $10 \mathrm{~nm}$ according to NLDFT. In contrast, the isotherms of the $50 \%$ and $80 \% \mathrm{NH}_{2}$-MIL samples show only a slightly reduced porosity of roughly $10-15 \%$, which indicates that the introduced mesoporosity is clearly less significant in terms of volume. The presence of a wide $\mathrm{H} 4$ hysteresis with the characteristics of cavitation-induced desorption reveals that these mesopores have access to the surface via entrances smaller than 4-5 nm. It, therefore, indicates a network of connected narrow, fracture-type mesopores. The proportion of large cavities is almost negligible for all samples with high $\mathrm{BDC}-\mathrm{NH}_{2}$ content (Fig. 6 and Supplementary Fig. 16) and decreases with increasing linker amount. Importantly, in all cases, the PSDs still show the presence of micropores with the same pore width of $0.6 \mathrm{~nm}$ as in the as-prepared samples. The combined results confirm that the selective ligand removal process at $300{ }^{\circ} \mathrm{C}$ retains the inherent microporous structure and introduces additional porosity through either cavity-type or fracture-type mesopores at low $\left(2-10 \% \mathrm{NH}_{2}-\mathrm{MIL}\right)$ and high $\mathrm{BDC}-\mathrm{NH}_{2}$ contents $\left(50-80 \% \mathrm{NH}_{2}\right.$ MIL), respectively.

We performed DFT calculations of several MIL framework models and followed their structural integrity after a part of the ligands was removed simulating the carboxylate-cleavage mechanism. Figure 7 exemplarily shows the basic unit cell of MIL that has 0,4 , and 6 out of 12 ligands removed (details are given in Supplementary Fig. 18). Our models indicate that only a negligible structural distortion takes place when four or fewer ligands are removed (this corresponds to $33 \%$ of all ligands), which is in line with the structural flexibility of such frameworks ${ }^{48}$. In contrast, when six or more ligands are removed (corresponding to more than $50 \%$ of all ligands), the calculated distortions become significant, yet the physisorption data show that the inherent microporosity is largely preserved. As mentioned, in situ XRD shows no significant changes in 

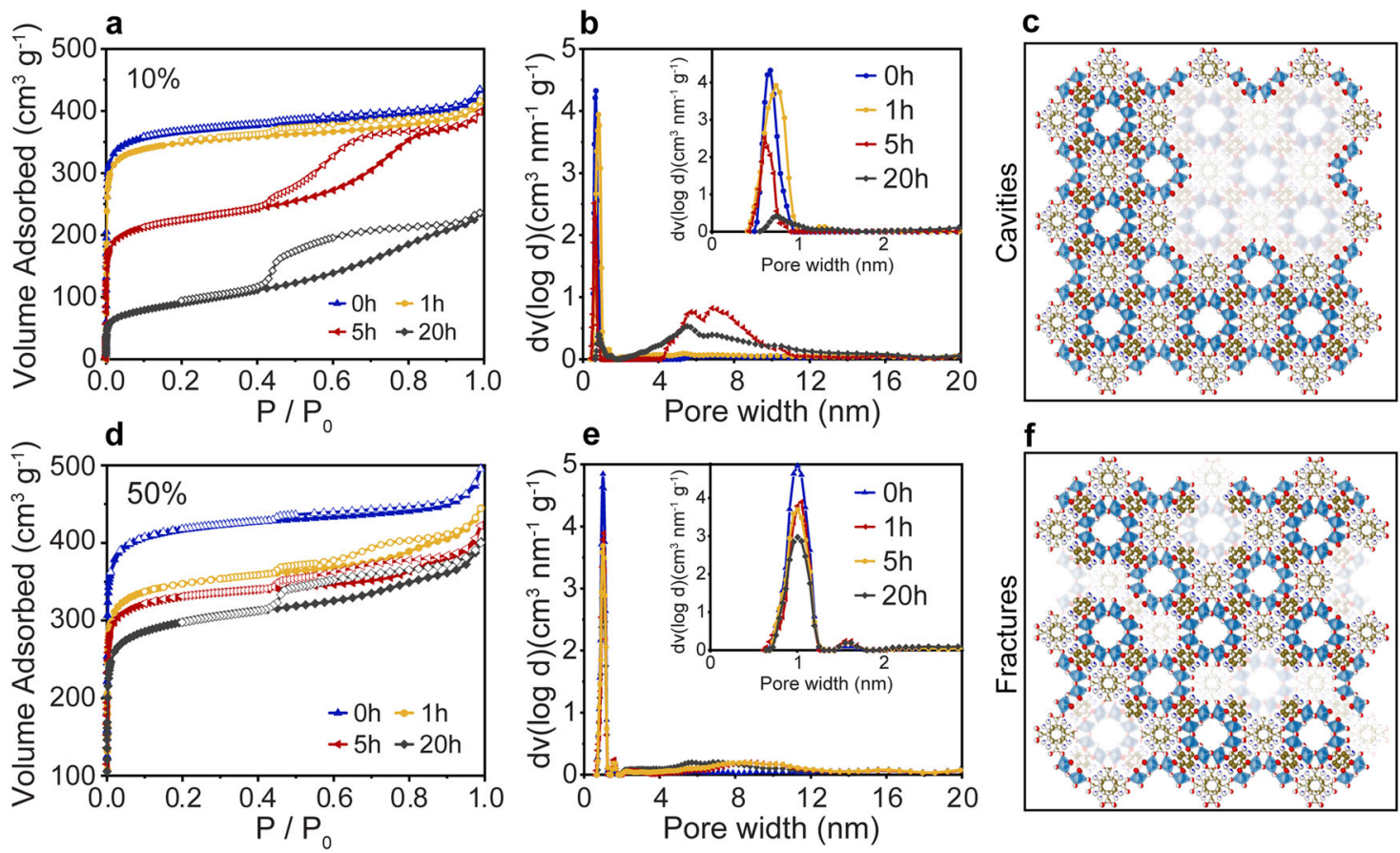

Fig. 6 Characterization of added mesopores. a, $\mathbf{d}$ Ar physisorption isotherms at $87 \mathrm{~K}$ for $10 \%$ and $50 \% \mathrm{NH}_{2}-\mathrm{MIL}$ respectively, for as-prepared samples and those heated at $300^{\circ} \mathrm{C}$ for 1,5 and $20 \mathrm{~h}$. b, e The corresponding NLDFT pore size distributions (adsorption branch) for $10 \%$ and $50 \% \mathrm{NH}_{2}-\mathrm{MIL}$. c, $\mathbf{f}$ Schematic representations of the mesopores reflecting cavity-type pore structures and fracture-type pores, respectively.
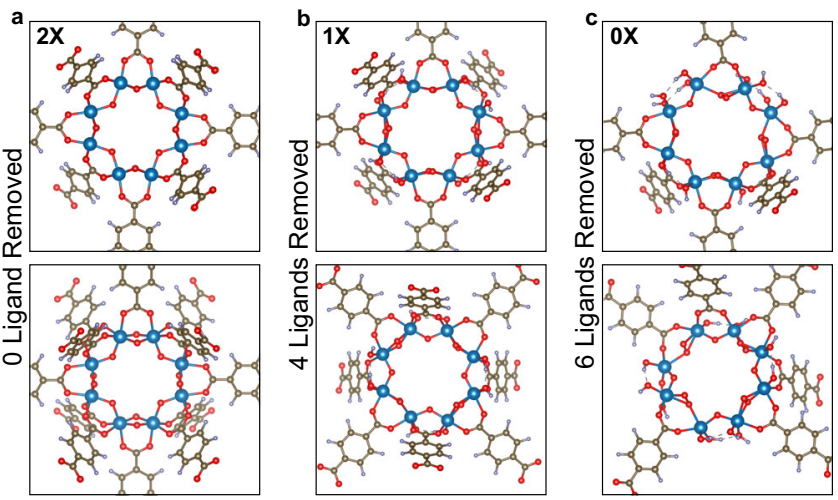

Fig. 7 DFT simulations. Schematic representations (top view and tilted) of the MIL frameworks with 0 (a), 4 (b) and 6 (c) ligands out of 12 ligands removed. A slight distortion of the pores can be seen in case $\mathrm{c}$.

structure, even for $80 \% \mathrm{NH}_{2}$-MIL (Supplementary Figs. 12 and 13). This apparent discrepancy is likely due to the assumption that the two ligands in the frameworks are homogeneously distributed. However, the formation of mesopores upon selective ligand removal of $\mathrm{BDC}-\mathrm{NH}_{2}$ suggests a certain degree of heterogeneity and ligand clustering ${ }^{49}$. It is thus plausible that the resulting frameworks, even originating from $80 \% \mathrm{NH}_{2}$-MIL, do not experience the simulated distortion.

Photocatalytic evaluation. The photocatalytic properties of all as-prepared samples, as well as those heated at $30{ }^{\circ} \mathrm{C}$ for 1,5 , and $20 \mathrm{~h}$, were investigated towards sacrificial hydrogen generation (HER) from aqueous methanol solutions, using a dedicated flow-reactor and a product monitoring system that allows for online detection of $\mathrm{H}_{2}$ and $\mathrm{CO}_{2}$ from the start of the process. The relatively large band gap of MIL of $3.6 \mathrm{eV}$ mandates the use of a
UV light source for fair activity comparison ${ }^{50}$. Pt was added as a co-catalyst via in situ photodeposition ${ }^{51,52}$. TEM images reveal that the Pt nanoparticles are predominantly located on the surface of the MOF particles and that neither their average size of $\sim 2 \mathrm{~nm}$ nor their dispersion has noticeably changed during the HER reaction (Supplementary Fig. 19). In addition, XRD and TEM also show no significant changes in the structure after $3 \mathrm{~h}$ of HER; note that only the $10 \% \mathrm{NH}_{2}$-MIL sample that was heated at $300{ }^{\circ} \mathrm{C}$ for $20 \mathrm{~h}$ shows some minor signs of corrosion (Supplementary Fig. 20).

The as-recorded $\mathrm{H}_{2}$ evolution plots are summarized in Supplementary Fig. 21a-d and reveal that in all samples the rates reach saturation within $20-30 \mathrm{~min}$ and remain stable for at least several hours. Figure $8 \mathrm{a}, \mathrm{b}$ compares the saturation rates taken after $3 \mathrm{~h}$ of HER - for as-prepared and heat-treated $10 \%$ and $50 \% \mathrm{NH}_{2}$-MIL (for the other samples refer to Supplementary Fig. 22). It is clear that the heat treatment has a pronounced effect on the HER rates. The samples with $10 \%$ or lower $\mathrm{BDC}-\mathrm{NH}_{2}$ contents heated for $1 \mathrm{~h}$ show a slightly lower rate than the asprepared samples. Note that heating at this stage has only removed DMF solvent molecules. In contrast, the samples 50\% and $80 \% \mathrm{NH}_{2}$-MIL show a small increase in rate. This may be connected with an earlier start of BDC- $\mathrm{NH}_{2}$ removal in those samples, as indicated by the earlier formation of $\mathrm{OH}$ bands $\left(3615 \mathrm{~cm}^{-1}\right)$ associated with bond cleavage (Supplementary $\left.15 b\right)$.

The rates of the heated samples $(5 \mathrm{~h})$ are considerably higher than those of the as-prepared samples. Note that there is a major difference in the extent of rate enhancement that seems to be linked to the type of porosity. The samples with cavity-type pores $\left(2-10 \% \mathrm{NH}_{2}-\mathrm{MIL}\right)$ exhibit a rate increase of about 1.4-1.5 times, while those containing interconnected fracture-type pores $(50 \%$ and $80 \% \mathrm{NH}_{2}$-MIL) experience a much more pronounced $4-5$ times enhancement. Changes in size and location of the Pt cocatalyst between the samples appear too small (Supplementary Fig. 19) to impact the HER rate to this extent. A contribution by $\mathrm{TiO}_{2}$ nanoclusters smaller than the detection limit $(<1 \mathrm{~nm})$ seems 

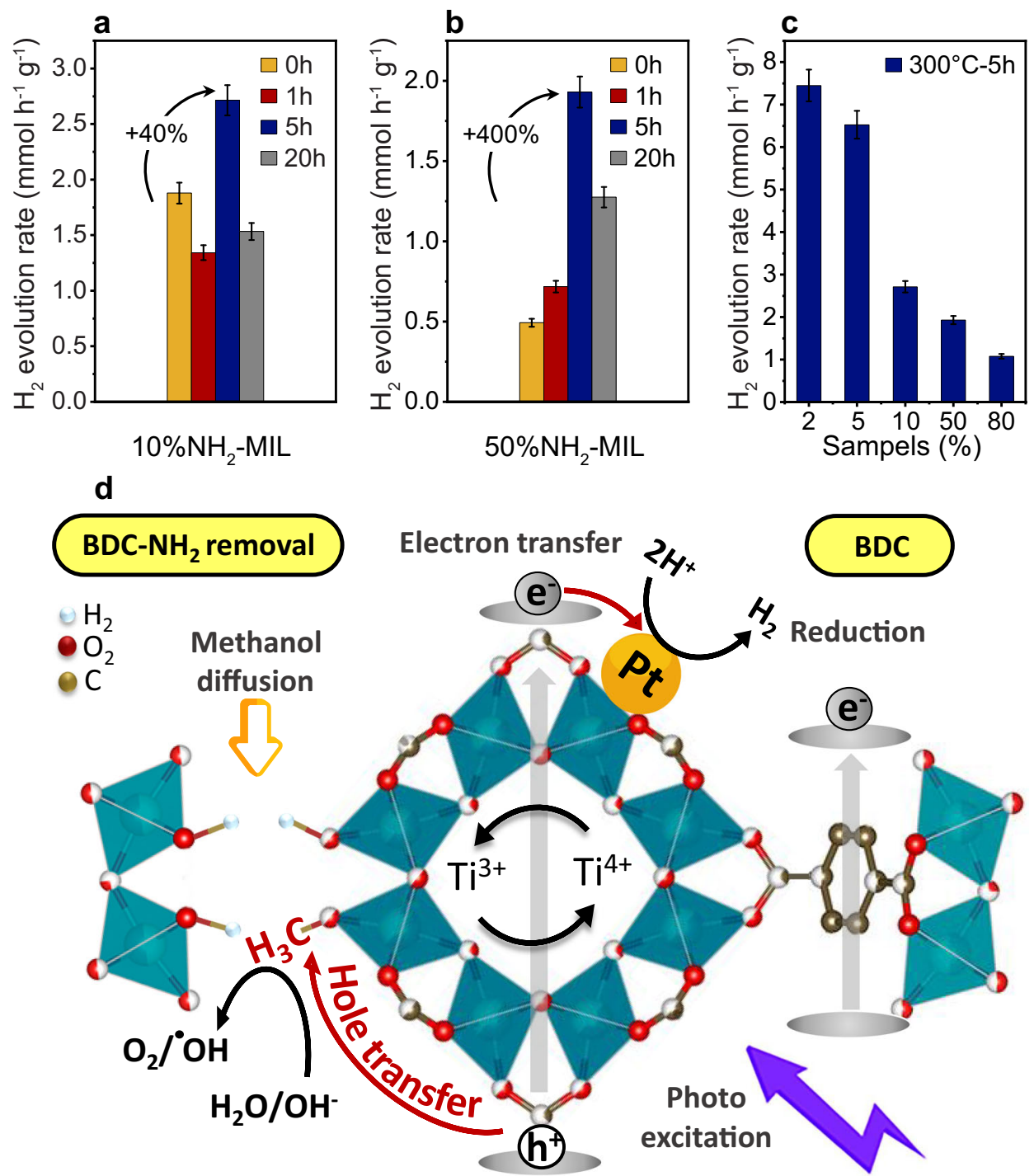

Fig. 8 Photocatalytic studies and mechanistic models. a, b Photocatalytic hydrogen evolution rates after $3 \mathrm{~h} \mathrm{HER} \mathrm{reaction} \mathrm{for} 10 \%$ and $50 \% \mathrm{NH}_{2}-\mathrm{MIL}_{\mathrm{L}}$ asprepared and heat-treated MOFs at $300^{\circ} \mathrm{C}$ for 1,5 , and $20 \mathrm{~h}$. c Photocatalytic hydrogen evolution rates for all samples $2-80 \% \mathrm{NH}_{2}-\mathrm{MIL}$ heat-treated MOFs at $300^{\circ} \mathrm{C}$ for $5 \mathrm{~h}$. d Proposed mechanism for photocatalytic HER on MOFs after selective ligand removal.

unlikely in light of the complementary characterization methods, but cannot be fully excluded and requires future investigations.

The apparent correlation between rate enhancement and type of mesopores suggests that the formation of additional active sites upon selective ligand removal (i.e., terminal $\mathrm{OH}$ groups in the SBU) and their enhanced accessibility via reactant diffusion through large, preferably 3D-interconnected mesopores are key to the enhanced performance. This hypothesis is supported by the increased formation of $\mathrm{CO}_{2}$ in the heat-treated samples (Supplementary Fig. 23), where the sacrificial agent methanol can more easily enter the pores, adsorb and get oxidized at the newly created $\mathrm{OH}$ groups. It further complies with the observed decrease in rate with samples treated for $20 \mathrm{~h}$, which is explained by surface corrosion leading to a partial pore collapse and blockade of active sites (Supplementary Fig. 20). In addition, a more efficient charge separation at the newly formed active sites (hole trapping via methoxy formation) as well as changes in electronic structure of the MOFs, as revealed by diffuse reflectance spectroscopy (DRS) (Supplementary Fig. 25b), will likely affect the photocatalytic performance as well. Although these observations seem quite conclusive, future studies are required to investigate the effects of selective ligand removal on the band positions and defect structure, the nature of active Lewis sites $^{53}$ and the charge separation dynamics in order to fully understand their role in enhancing the photocatalytic activity in heat-treated MOFs.

In recent work, we reported that the presence of $\mathrm{BDC}-\mathrm{NH}_{2}$ is detrimental to the photocatalytic performance ${ }^{50}$. Essentially, photoexcitation of the organic ligand leads to electron transfer to Ti sites of the SBU, leaving the respective holes localized either at $\mathrm{N}$ in the ligand (for $\mathrm{NH}_{2}-\mathrm{MIL}$ ), or at $\mathrm{O}$ in the SBU (for MIL). During the reaction, methanol adsorbs on $\mathrm{Ti}$ as methoxy groups that are capable of scavenging nearby holes, i.e., those from a neighboring $\mathrm{O}$ in $\mathrm{MIL}$, while the nitrogen-localized holes in $\mathrm{NH}_{2}$-MIL are too far away for effective scavenging (Supplementary Fig. 26). Figure $8 \mathrm{c}$ shows that rates of the heat-treated MOFs decrease with increasing amino content. This is attributed to the presence of small amounts of residual $\mathrm{BDC}-\mathrm{NH}_{2}$ (or degradation products) after ligand removal, in line with DRIFTS and NMR spectroscopy. Consequently, although the $2 \%$ and $5 \%$ $\mathrm{NH}_{2}$-MIL samples already outperform MIL and other photoactive $\mathrm{MOFs}^{54,55}$, it is likely that a more complete elimination of 


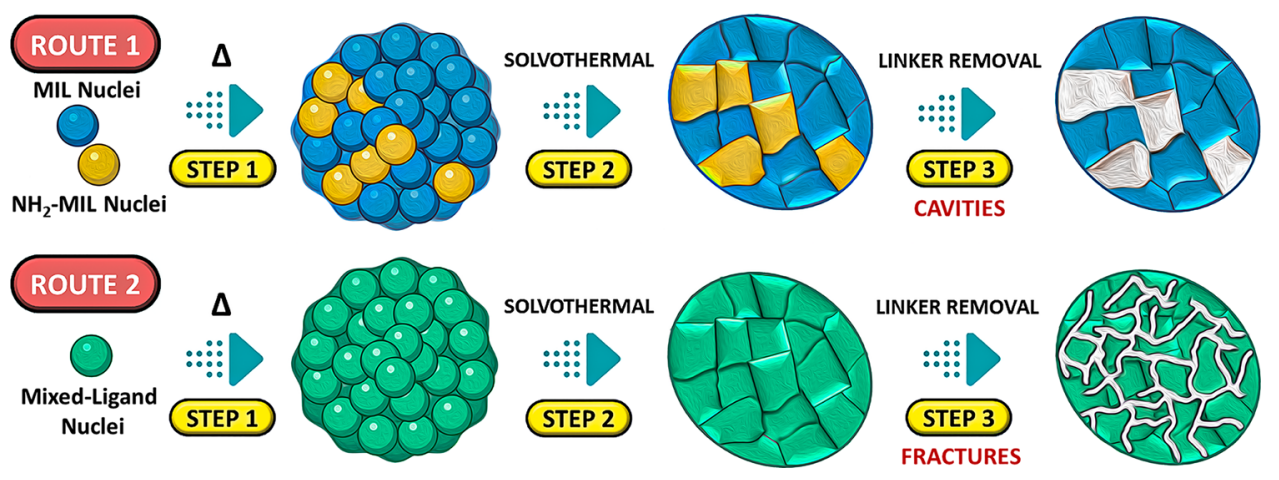

Fig. 9 Mechanistic model of the MOFs formation. Proposed mechanism of the MOFs formation via solvothermal for samples $2-10 \% \mathrm{NH}_{2}-\mathrm{MIL}^{2}$ and $50-80 \%$ $\mathrm{NH}_{2}-\mathrm{MIL}$, ranging from the formation of amorphous nuclei to crystal with selective ligand removal.

BDC- $\mathrm{NH}_{2}$ via process optimizations will further enhance the HER performance.

Hypothesis on the formation of different pore structures. The results show that the pore structure and hence the synthesis route has a marked effect on the pore structure and the resulting enhancements in HER activity. The selective ligand removal from the $2 \%$ and $10 \% \mathrm{NH}_{2}$-MIL samples produced via route 1 (BDC$\mathrm{NH}_{2}$ added to the BDC-TTIP solution) yields cavity-type pores with uniform diameters that increased the activity by 1.4-1.5 times while it introduces branching fracture-type pores to the MOFs obtained via route 2 (BDC added to the $\mathrm{BDC}-\mathrm{NH}_{2}-$ TTIP solution) resulting in much larger enhancements of about 5-6 times. Most works to date used post-synthetic ligand exchange to create mixed-ligand MOFs, which either resulted in the coexistence of randomly sized areas containing only singleligands (i.e., fast ligand diffusion) or in the formation of distinct core-shell particles (i.e., slow ligand diffusion) ${ }^{56}$. However, none of these morphologies can satisfactorily explain the observed pore structures, nor the different enhancement factors regarding the HER activity.

In contrast to previous studies, our synthesis approach incorporates both ligands in solution at room temperature before solvothermal crystallization, yet with different orders of ligand addition (Supplementary Fig. 1). Since we observed different pore structures of the heat-treated MOFs for the two routes, the order of ligand addition must have an impact already at the stage of nucleation. To develop this hypothesis, we need to consider the binding strength of both ligands with the SBU. Therefore, we performed DFT simulations of MIL and $\mathrm{NH}_{2}$-MIL frameworks bond lengths of the ligand-cluster bindings in both cases. Supplementary Figure 24 shows that the ligand coordination to the SBU in MIL is symmetric and yields an O-Ti bond length of $1.941 \AA$ A. In contrast, BDC- $\mathrm{NH}_{2}$ asymmetry provides coordination with two $\mathrm{O}-\mathrm{Ti}$ bond distances. The amino group can interact with one of the four oxygens of the two carboxylates, which weakens the effective $\mathrm{O}$ charge. As a result, this particular $\mathrm{O}-\mathrm{Ti}$ bond yields a longer $\mathrm{O}$-Ti distance of $1.987 \AA$. However, the length of the three remaining O-Ti bonds is $1.946 \AA$ (longer than for the MIL case) due to the electronic effects of the $\mathrm{NH}_{2}$ on the benzene ring. Overall, this indicates that $\mathrm{BDC}$ has stronger binding energy within the framework than $\mathrm{BDC}-\mathrm{NH}_{2}$.

We thus propose a mechanism (Fig. 9), where the addition of the metal precursor to the ligand solution initiates the formation of small, albeit amorphous nuclei that already resemble the ligand connectivity to the SBUs of the final MOFs. Due to the low solubility of both ligands in the DMF-methanol mixture, nucleation may be the dominant process at low temperatures.
In route 1 , where $\mathrm{BDC}-\mathrm{NH}_{2}$ is added to a pre-mixed $\mathrm{BDC}$ TTIP solution, most nuclei likely comprise of pure BDC-SBU, while the BDC- $\mathrm{NH}_{2}$ either attaches as shells or, more likely, forms separate $\mathrm{BDC}-\mathrm{NH}_{2}-\mathrm{SBU}$ nuclei that fuse together during the solvothermal process. It is thus plausible that the MOF particles in this process are essentially assemblies of the initial, pure-ligand nuclei, which connect upon crystallization. Upon heat treatment, the parts resembling the $\mathrm{BDC}-\mathrm{NH}_{2}$ nuclei are removed preferably, resulting in cavity-type pores in the MOF particle.

In route 2 , the addition of $\mathrm{BDC}$ to $\mathrm{BDC}-\mathrm{NH}_{2}-\mathrm{SBU}$ nuclei enacts a partial ligand exchange due to stronger interactions between BDC and the SBU, thus creating mixed-ligand nuclei already at low temperatures. The solvothermal process then leads to aggregation and subsequent crystallization into mixed-ligand MOF particles with the $\mathrm{BDC}-\mathrm{NH}_{2}$ ligand being relatively welldispersed throughout the entire framework. Upon heat treatment, the selective removal of $\mathrm{BDC}-\mathrm{NH}_{2}$ ligands thus yields extended, but narrow fracture-type pores that are, at least partially, interconnected throughout the MOF particle.

In both cases, the overall framework structure remains preserved upon heat treatment, as confirmed by XRD, physisorption, and DFT simulations, while XPS, SAED, and Raman exclude the formation of $\mathrm{TiO}_{2}$ nanoparticles. The type of generated mesopores then plays a dominant role in the photocatalytic enhancement, and it appears that the fracture-type mesopores ( $50 \%$ and $80 \% \mathrm{NH}_{2}$-MIL) with their $3 \mathrm{D}$ pore connectivity (i.e., improved reactant diffusion) and larger surface areas (i.e., more active sites) show stronger improvements than the cavity-type larger mesopores $\left(2 \%, 5 \%, 10 \% \mathrm{NH}_{2}\right.$-MIL).

In conclusion, we produced a series of photoactive MOFs of the MIL family containing dual-porosity using a highly selective ligand removal process from mixed-ligand MOFs. Careful adjustment of synthesis conditions and heating parameters yielded either isolated cavity-type mesopores of uniform diameter (2-10\% $\left.\mathrm{NH}_{2}-\mathrm{MIL}\right)$ or branched, narrow fracture-type pores (50-80\% $\left.\mathrm{NH}_{2}-\mathrm{MIL}\right)$, without the typically associated collapse of the micropore structure. We analyzed the ligand removal process thoroughly with a large set of ex situ and in situ techniques, including XRD, DRIFTS, TGA/DSC, SEM, SAED/TEM, XPS, Raman, Ar physisorption, and ${ }^{1}$ HNMR spectroscopy, supported by DFT simulations. The ligand removal is highly selective towards $\mathrm{BDC}-\mathrm{NH}_{2}$ and follows a 2-step process that can be well controlled by adjusting temperature and time. The results show that the inherent framework remained intact, even after the removal of $>50 \%$ of the ligands with no visible signs of any oxide nanoparticle formation. This is explained by a certain degree of heterogeneity in the inherent ligand distribution that is expected from the observed formation of mesopores upon heat treatment. 
The introduction of both types of mesopores has greatly enhanced the photocatalytic properties of the MOFs towards hydrogen evolution. Note that it is the fracture-type geometry with its mesopore connectivity that has enhanced the activity by unprecedented levels (up to 5-times with respect to the asprepared mixed-ligand MOF). We attribute this mainly to the formation of new active sites, their enhanced accessibility via reactant diffusion through the interconnected mesopores and an improved charge separation efficiency. It remains for future studies to evaluate the impact of selective ligand removal on changes in band positions and inter-band gap states as well as on the nature of Lewis sites and their role as adsorption sites and charge recombination centers. Therefore, this work provides an intriguing example for rationalized pore engineering in MOFs to design model systems for fundamental studies and to advance their applications in liquid reaction media including photocatalysis, photovoltaics, electrocatalysis, and electrochemical sensing.

\section{Methods}

Synthesis of mixed-ligand MOFs. A series of mixed-ligand MOFs was prepared by applying a certain amount of both ligands ( $\mathrm{BDC}$ and $\mathrm{BDC}-\mathrm{NH}_{2}$ ) to yield a series of samples with BDC- $\mathrm{NH}_{2}$ mol.\% equal to $2,5,10,50,80$. In a single synthesis, addition of TTIP $(0.592 \mathrm{~mL})$, BDC ( $1000 \mathrm{mg}$ for $2 \%, 5 \%, 10 \%$ and 249 and $99.8 \mathrm{mg}$ for $50 \%$ and $80 \%$ respectively), BDC- $\mathrm{NH}_{2}(22.2,57.2,120.8,271.7,434.7 \mathrm{mg}$, respectively), to a solution of DMF and methanol $(20 \mathrm{~mL}$ for $2 \%, 5 \%, 10 \%$ and $40 \mathrm{~mL}$ for $\left.50 \%, 80 \%, V_{\mathrm{DMF}} / V_{\text {methanol }}=9: 1\right)$ was poured in a $100 \mathrm{~mL}$ Teflon-lined steel autoclave. The mixture was heated at $150^{\circ} \mathrm{C}$ for $18 \mathrm{~h}(2 \%, 5 \%$, and $10 \%)$ and $24 \mathrm{~h}(50 \%$, and $80 \%)$. As the nondominant linker is dispersing in the matrix of dominant linker ${ }^{49}$, there are 2 different routes to synthesis mixed-ligand MOFs: route 1 is based on adding BDC-NH $\mathrm{NH}_{2}$ to the MIL-125-Ti precursor and route 2 is adding BDC ligand to $\mathrm{NH}_{2}$-MIL precursor. The samples with $2 \%, 5 \%$, and $10 \%$ of $\mathrm{NH}_{2}$ content were synthesized by route 1 , and route 2 was applied to prepare $50 \%$ and $80 \%$. After cooling to room temperature, the resulting powder was washed with DMF three times and twice with methanol to remove the unreacted ligand and separated by centrifugation and dried under vacuum at $150^{\circ} \mathrm{C}$ for 1 day.

Heat-treated MOFs. Two protocols followed: (1) The samples were heated in air with a constant ramp $\left(10^{\circ} \mathrm{C} \mathrm{min}^{-1}\right)$ up to $550^{\circ} \mathrm{C}$. (2) The samples were heated to $300^{\circ} \mathrm{C}$ with a constant ramp $\left(10^{\circ} \mathrm{C} \mathrm{min}^{-1}\right)$ and kept at that temperature for durations up to $20 \mathrm{~h}$. In both cases, the samples were allowed to cool down to room temperature.

Argon physisorption isotherms. Physisorption isotherms were measured on a Quantatec iQ2 instrument equipped with the cryosync accessory using Ar at $87 \mathrm{~K}$. The surface area was quantified via BET following the procedure recommended for microporous sorbent $\mathrm{s}^{57}$. The pore size distributions were calculated by applying the kernel of (metastable) nonlocal density functional theory (NLDFT) adsorption isotherms.

X-ray Diffraction. XRD profiles were recorded on a PANalytical X'Pert Pro multipurpose diffractometer (MPD) in Bragg Brentano geometry operating with a $\mathrm{Cu}$ anode at $45 \mathrm{kV}, 40 \mathrm{~mA}$, equipped with a BBHD Mirror and an X-Celerator multichannel detector. All measurements were conducted with a $\mathrm{Cu}$ sealed tube $\mathrm{Ka}$ and $\mathrm{K} \beta$ radiation $\left(2: 1\right.$ ratio) source $(\lambda=1.5406 \AA)$ at a scan rate of $0.5^{\circ} \mathrm{min}^{-1}$.

Scanning electron microscope. SEM images were acquired on a FEI Quanta 250 FEG SEM with an acceleration voltage of $10 \mathrm{KV}$.

Transmission electron microscope. TEM BF images and SAED patterns were recorded on a FEI Tecnai F20 Transmission Electron Microscope (TEM) with an electron acceleration voltage of $200 \mathrm{kV}$.

Raman spectroscopy. Raman measurements employed Horiba Jobin-Yvon LabRAM $800 \mathrm{HR}$ and were carried out using a $532 \mathrm{~nm}$ wavelength green laser.

Crystallographic phase analysis. Qualitative phase analysis was carried out by comparison to literature and to the International Centre for Diffraction Data (ICDD) using PDF4+ 2021 software. The phase analysis of mixed-ligand MOFs based on MIL-125-Ti MOF was carried out using the cif file provided in reference ${ }^{30}$. The following PDF files were used for phase identification of anatase $\mathrm{TiO}_{2}$ : 04-011-0664.
X-ray photoelectron spectroscopy. XPS spectra were acquired in a UHV chamber (base pressure $<3 \times 10^{-10} \mathrm{mbar}$ ) equipped with a Specs $\mathrm{XR} 50^{\circ}$ highintensity non-monochromatic $\mathrm{Al} / \mathrm{Mg}$ dual anode and a Phoibos $100^{\odot}$ hemispherical electron energy analyzer with multichannel plate detector ${ }^{58}$.

UV-Vis diffuse reflectance spectra. UV-Vis spectra were measured on a Jasco V-670. The light was collected with an Ulbricht-sphere and the incident light was in the range of $300-800 \mathrm{~nm}$.

In situ XRD. In situ XRD was measured on a PANalytical, X'Pert Pro MPD diffractometer system, conducted with $\mathrm{Cu}-\mathrm{K} \alpha 1,2$ radiation $(\lambda=1.54060 \AA$, $1.54439 \AA$ ) and equipped with an X-Celerator multichannel detector using Bragg Brentano geometry. The samples were heated with an Anton Paar HTK $1200 \mathrm{~N}$ oven.

In situ diffuse reflectance for infrared fourier transform spectroscopy. DRIFTS data were measured on IR Tracer-100 under air atmosphere. The instrument was equipped with a controlled heating device.

Thermogravimetric analysis. TGA measurements were conducted on a PerkinElmer. Thermogravimetric analyzer 8000 , using aluminum oxide $\left(\mathrm{Al}_{2} \mathrm{O}_{3}\right)$ crucible.

Differential scanning calorimetry. DSC was performed at a heating rate of $10^{\circ} \mathrm{C} \mathrm{min}-1$ under air atmosphere with a $20 \mathrm{~mL} \mathrm{~min}^{-1}$ flow rate over a temperature range of $50-600^{\circ} \mathrm{C}$.

Nuclear magnetic resonance spectroscopy ('HNMR). The liquid phase ${ }^{1} \mathrm{H}$ spectra were recorded on a Bruker AVANCE $250(250.13 \mathrm{MHz})$ equipped with a $5 \mathrm{~mm}$ inverse-broad probe head and z-gradient unit.

Density-functional theory. DFT calculations were performed by using the Vienna ab initio simulation package (VASP 5.4.1) under spin-polarized density functional theory (DFT). Detailed information are given in Supplementary Information.

Photocatalysis experiments. We used a home-made continuous-flow reactor equipped with an online gas detection system from Emerson (X-Stream) that simultaneously monitors $\mathrm{H}_{2}, \mathrm{O}_{2}, \mathrm{CO}$, and $\mathrm{CO}_{2}$. As a light source a 200-W superpressure Hg lamp $(\lambda=240-500 \mathrm{~nm}, I=30 \mathrm{mWcm}-2$, Superlite SUV DC-P deep UV, Lumatec) equipped with an optical fiber light guide was used.

\section{Data availability}

Additional data on methods, materials characterizations and photocatalytic performance are available in Supplementary Information. Source data are provided on this platform (10.5281/zenodo.5727081)

Received: 20 May 2021; Accepted: 8 December 2021; Published online: 12 January 2022

\section{References}

1. Zhou, H.-C., Long, J. R. \& Yaghi, O. M. Introduction to metal-organic frameworks. Chem. Rev. 112, 673-674 (2012).

2. Stock, N. \& Biswas, S. Synthesis of metal-organic frameworks (MOFs): routes to various mof topologies, morphologies, and composites. Chem. Rev. 112, 933-969 (2012).

3. Zhang, T. \& Lin, W. Metal-organic frameworks for artificial photosynthesis and photocatalysis. Chem. Soc. Rev. 43, 5982-5993 (2014).

4. Wang, S. \& Wang, X. Multifunctional metal-organic frameworks for photocatalysis. Small 11, 3097-3112 (2015).

5. Shiozawa, H. et al. Doping of metal-organic frameworks towards resistive sensing. Sci. Rep. 7, 2439 (2017).

6. Hu, S. et al. Solvothermal synthesis of NH 2 -MIL-125(Ti) from circular plate to octahedron. CrystEngComm 16, 9645-9650 (2014).

7. Li, Y., Xu, H., Ouyang, S. \& Ye, J. Metal-organic frameworks for photocatalysis. Phys. Chem. Chem. Phys. 18, 7563-7572 (2016).

8. Hall, J. N. \& Bollini, P. Structure, characterization, and catalytic properties of open-metal sites in metal organic frameworks. React. Chem. Eng. 4, 207-222 (2019).

9. Hou, C.-C., Wang, H.-F., Li, C. \& Xu, Q. From metal-organic frameworks to single/dual-atom and cluster metal catalysts for energy applications. Energy Environ. Sci. https://doi.org/10.1039/C9EE04040D (2020). 
10. Zeng, L., Guo, X., He, C. \& Duan, C. Metal-organic frameworks: versatile materials for heterogeneous photocatalysis. ACS Catal. 6, 7935-7947 (2016).

11. Zhang, H. et al. Engineering coordination polymers for photocatalysis. Nano Energy 22, 149-168 (2016).

12. Wu, C.-D. Crystal Engineering of Metal-Organic Frameworks for Heterogeneous Catalysis. in Selective Nanocatalysts and Nanoscience p. 271-298 (John Wiley \& Sons, Ltd, 2011).

13. Liu, J. et al. Applications of metal-organic frameworks in heterogeneous supramolecular catalysis. Chem. Soc. Rev. 43, 6011-6061 (2014).

14. Methods of Creating Active Sites in MOF and Catalytic Explorations | Request PDF. ResearchGate https://www.researchgate.net/publication/ 296836386_Methods_of_Creating_Active_Sites_in_MOF_and_Catalytic_Explorations.

15. Li, P.-Z. et al. Clicked isoreticular metal-organic frameworks and their high performance in the selective capture and separation of large organic molecules. Angew. Chem. Int. Ed. 54, 12748-12752 (2015).

16. Evans, J. D. et al. Metal-organic frameworks in Germany: From synthesis to function. Coord. Chem. Rev. 380, 378-418 (2019).

17. Fang, Q.-R. et al. Mesoporous metal-organic framework with rare etb topology for hydrogen storage and dye assembly. Angew. Chem. Int. Ed. 46, 6638-6642 (2007).

18. Park, J., Wang, Z. U., Sun, L.-B., Chen, Y.-P. \& Zhou, H.-C. Introduction of Functionalized Mesopores to Metal-Organic Frameworks via Metal-Ligand-Fragment Coassembly. J. Am. Chem. Soc. 134, 20110-20116 (2012).

19. Choi, K. M., Jeon, H. J., Kang, J. K. \& Yaghi, O. M. Heterogeneity within order in crystals of a porous metal-organic framework. J. Am. Chem. Soc. 133, 11920-11923 (2011).

20. Klein, N. et al. A mesoporous metal-organic framework. Angew. Chem. Int. Ed. 48, 9954-9957 (2009).

21. Huang, H. et al. An in situ self-assembly template strategy for the preparation of hierarchical-pore metal-organic frameworks. Nat. Commun. 6, 1-8 (2015).

22. Wu, Y. et al. Metal-organic frameworks with a three-dimensional ordered macroporous structure: dynamic photonic materials. Angew. Chem. Int. Ed. Engl. 50, 12518-12522 (2011).

23. Qiu, L.-G. et al. Hierarchically micro- and mesoporous metal-organic frameworks with tunable porosity. Angew. Chem. Int. Ed. 47, 9487-9491 (2008).

24. Cai, G. \& Jiang, H.-L. A modulator-induced defect-formation strategy to hierarchically porous metal-organic frameworks with high stability. Angew. Chem. Int. Ed. 56, 563-567 (2017).

25. Qi, S.-C. et al. Generation of hierarchical porosity in metal-organic frameworks by the modulation of cation valence. Angew. Chem. Int. Ed. 58, 10104-10109 (2019).

26. Karagiaridi, O., Bury, W., Mondloch, J. E., Hupp, J. T. \& Farha, O. K. Solventassisted linker exchange: an alternative to the de novo synthesis of unattainable metal-organic frameworks. Angew. Chem. Int. Ed. Engl. 53, 4530-4540 (2014).

27. Feng, L. et al. Creating hierarchical pores by controlled linker thermolysis in multivariate metal-organic frameworks. J. Am. Chem. Soc. 140, 2363-2372 (2018).

28. Li, P. et al. Hierarchically engineered mesoporous metal-organic frameworks toward cell-free immobilized enzyme systems. Chem. 4, 1022-1034 (2018).

29. Fu, Y. et al. An amine-functionalized titanium metal-organic framework photocatalyst with visible-light-induced activity for $\mathrm{CO}_{2}$ reduction. Angew. Chem. Int. Ed. 51, 3364-3367 (2012).

30. Dan-Hardi, M. et al. A new photoactive crystalline highly porous titanium(IV) dicarboxylate. J. Am. Chem. Soc. 131, 10857-10859 (2009).

31. Dhakshinamoorthy, A., Asiri, A. M. \& Garcia, H. Mixed-metal or mixedlinker metal organic frameworks as heterogeneous catalysts. Catal. Sci. Technol. 6, 5238-5261 (2016).

32. Liu, Y.-Y. et al. New V IV -based metal-organic framework having framework flexibility and high $\mathrm{CO}_{2}$ adsorption capacity. Inorg. Chem. 52, 113-120 (2013).

33. Planas, N. et al. Defining the Proton Topology of the Zr6-Based Metal-Organic Framework NU-1000. J. Phys. Chem. Lett. 5, 3716-3723 (2014).

34. Lu, A. X. et al. MOFabric: electrospun nanofiber mats from PVDF/UiO-66NH 2 for chemical protection and decontamination. ACS Appl. Mater. Interfaces 9, 13632-13636 (2017).

35. Oliveira, B. G., Lima, M. C. A., Pitta, I. R., Galdino, S. L. \& Hernandes, M. Z. A theoretical study of red-shifting and blue-shifting hydrogen bonds occurring between imidazolidine derivatives and PEG/PVP polymers. J. Mol. Model 16, 119-127 (2010).

36. IR Spectrum Table \& Chart. Sigma-Aldrich https://www.sigmaaldrich.com/ technical-documents/articles/biology/ir-spectrum-table.html.
37. Ye, F., Li, H., Yu, H., Chen, S. \& Quan, X. Hydrothermal fabrication of fewlayer MoS2 nanosheets within nanopores on TiO2 derived from MIL-125(Ti) for efficient photocatalytic H2 evolution. Appl. Surf. Sci. 426, 177-184 (2017).

38. Guo, Z. et al. Metal-organic frameworks (MOFs) as precursors towards $\mathrm{TiOx} /$ C composites for photodegradation of organic dye. RSC Adv. 4, 34221-34225 (2014).

39. Ji, P. et al. Titanium(III)-oxo clusters in a metal-organic framework support single-site Co(II)-hydride catalysts for arene hydrogenation. J. Am. Chem. Soc. 140, 433-440 (2018).

40. Schubert, J. S. et al. Elucidating the formation and active state of $\mathrm{Cu}$ cocatalysts for photocatalytic hydrogen evolution. J. Mater. Chem. A https:// doi.org/10.1039/D1TA05561E (2021).

41. Williams, D. B. \& Carter, C. B. The Transmission Electron Microscope. in Transmission Electron Microscopy: A Textbook for Materials Science (Williams, D. B. \& Carter, C. B. eds.) 3-22 (Springer US, 2009).

42. Bayer, B. C. et al. In situ observations of phase transitions in metastable nickel (carbide)/carbon nanocomposites. J. Phys. Chem. C. 120, 22571-22584 (2016).

43. Hlophe, P. V. \& Dlamini, L. N. Synthesis of a semi-conductor-like MOF with black phosphorous as a composite for visible light-driven photocatalysis. RSC Adv. 9, 37321-37330 (2019)

44. Zhang, Q. et al. Anodic oxidation synthesis of one-dimensional TiO2 nanostructures for photocatalytic and field emission properties. J. Nanomater. 2014, e831752 (2014).

45. Chavan, S. et al. H 2 storage in isostructural UiO-67 and UiO-66 MOFs. Phys. Chem. Chem. Phys. 14, 1614-1626 (2012).

46. Zhou, F., Zhou, J., Gao, X., Kong, C. \& Chen, L. Facile synthesis of MOFs with uncoordinated carboxyl groups for selective $\mathrm{CO}_{2}$ capture via postsynthetic covalent modification. RSC Adv. 7, 3713-3719 (2017).

47. Thommes, M. et al. Physisorption of gases, with special reference to the evaluation of surface area and pore size distribution (IUPAC Technical Report). Pure Appl. Chem. 87, 1051-1069 (2015).

48. Schneemann, A. et al. Flexible metal-organic frameworks. Chem. Soc. Rev. 43 6062-6096 (2014).

49. Feng, L., Wang, K.-Y., Day, G. S. \& Zhou, H.-C. The chemistry of multicomponent and hierarchical framework compounds. Chem. Soc. Rev. 48, 4823-4853 (2019).

50. Wang, J. et al. Ti-based MOFs: new insights on the impact of ligand composition and hole scavengers on stability, charge separation and photocatalytic hydrogen evolution. Appl. Catal. B Environ. 283, 119626 (2021).

51. Haselmann, G. M. \& Eder, D. Early-stage deactivation of platinum-loaded $\mathrm{TiO} 2$ using in situ photodeposition during photocatalytic hydrogen evolution. ACS Catal. 7, 4668-4675 (2017).

52. Haselmann, G. M. et al. In situ Pt photodeposition and methanol photooxidation on $\mathrm{Pt} / \mathrm{TiO} 2$ : Pt-loading-dependent photocatalytic reaction pathways studied by liquid-phase infrared spectroscopy. ACS Catal. 10, 2964-2977 (2020).

53. Zhu, Y. et al. Copper-zirconia interfaces in UiO-66 enable selective catalytic hydrogenation of $\mathrm{CO}_{2}$ to methanol. Nat. Commun. 11, 5849 (2020).

54. Santaclara, J. G. et al. Organic linker defines the excited-state decay of photocatalytic MIL-125(Ti)-type materials. ChemSusChem 9, 388-395 (2016)

55. Capano, G. et al. On the electronic and optical properties of metal-organic frameworks: case study of MIL-125 and MIL-125-NH2. J. Phys. Chem. C https://doi.org/10.1021/acs.jpcc.9b09453 (2020).

56. Pullen, S. \& Clever, G. H. Mixed-Ligand Metal-Organic Frameworks and Heteroleptic Coordination Cages as Multifunctional Scaffolds-A Comparison. Acc. Chem. Res. 51, 3052-3064 (2018).

57. Sánchez-Varretti, F. O., García, G. D., Ramirez-Pastor, A. J. \& Romá, F. A simple model for studying multilayer adsorption of noninteracting polyatomic species on homogeneous and heterogeneous surfaces. J. Chem. Phys. 130, 194711 (2009)

58. Haunold, T. \& Rupprechter, G. LiOx-modification of Ni and Co3O4 surfaces: An XPS, LEIS and LEED study. Surf. Sci. 713, 121915 (2021).

\section{Acknowledgements}

This research was funded in whole, or in part, by the Austrian Science Fund (FWF, I 5413-N, S.N.). The authors acknowledge the use of facilities at the University Service Centre for Transmission Electron Microscopy (USTEM) and the X-Ray Center (XRC), both located at the TU Wien, as well as financial support of the Vienna University of Technology, the University of Vienna, as well as via the Nancy and Stephen Grand Technion Energy Program (GTEP, upon work from COST Action CA18234, supported by COST (European Cooperation in Science and Technology), M.C.T.). Shaghayegh Naghdi acknowledges the valuable assistance and discussion from Mohammad Zendehbad from the Department of Water, Atmosphere and Environment, University of Natural Resources and Life Sciences Vienna (BOKU), Austria. 


\section{Author contributions}

S.N.: literature survey, methodology, main data acquisition and analysis, and manuscript draft writing. A.C.: discussion of photocatalysis and manuscript draft writing. A.G.: TEM experiments and DRIFTS data analysis. J.W.: additional SEM experiments. R.G.N. and F.K.: gas adsorption-desorption studies. T.G. and B.C.B.: TEM/SAED analysis. T.G.: Raman spectroscopy. T.H. and G.R.: XPS measurements and analysis. S.B. and M.C.T.: DFT calculations. D.E.: conceptualization, supervision, project administration, funding acquisition, and manuscript writing. All authors have approved the manuscript.

\section{Competing interests}

The authors declare no competing interests.

\section{Additional information}

Supplementary information The online version contains supplementary material available at https://doi.org/10.1038/s41467-021-27775-7.

Correspondence and requests for materials should be addressed to Dominik Eder.

Peer review information Nature Communications thanks the anonymous reviewer(s) for their contribution to the peer review of this work. Peer reviewer reports are available.
Reprints and permission information is available at http://www.nature.com/reprints

Publisher's note Springer Nature remains neutral with regard to jurisdictional claims in published maps and institutional affiliations.

(c) (i) Open Access This article is licensed under a Creative Commons Attribution 4.0 International License, which permits use, sharing, adaptation, distribution and reproduction in any medium or format, as long as you give appropriate credit to the original author(s) and the source, provide a link to the Creative Commons license, and indicate if changes were made. The images or other third party material in this article are included in the article's Creative Commons license, unless indicated otherwise in a credit line to the material. If material is not included in the article's Creative Commons license and your intended use is not permitted by statutory regulation or exceeds the permitted use, you will need to obtain permission directly from the copyright holder. To view a copy of this license, visit http://creativecommons.org/ licenses/by/4.0/.

(C) The Author(s) 2022 